UDK 631.358:633.521

(C) I. Dudarev, Sc.D., Yu. Hunko, PhD, S. Panasyuk, PhD Lutsk National Technical University, Lutsk, Ukraine

\title{
DETERMINATION OF DESIGN PARAMETERS OF THE CONICAL-DISK FLAX PULLING MECHANISM
}

The article deals with the study of the possibility of using the conical-disk flax pulling mechanism for the harvesting of linseed and fibre flax, which are intended for processing into short fibre. The design of conical-disk flax pulling mechanism has been proposed and can be installed on a flax puller of a new design or on cereals combine harvesters. The condition of pulling out the flax stems from the soil with conical-disk flax pulling mechanism was obtained. Theoretical study was allowed to determine the rational design parameters of conical-disk flax pulling mechanism. Technical length and total length of the stems of linseed and the force required for pulling out the stems from the soil were determined as a result of experimental study. According to the results of the study it was determined that the proposed conical-disk flax pulling mechanism can be used for harvesting linseed and fibre flax.

FIBRE FLAX, FLAX HARVESTING, FLAX PULLER, LINSEED, PROCESS OF FLAX PULLING OUT 
Introduction. The development of the flax industry in the world is due to the fact that flax is one of the few crops that have complex use [1-3]. There are two types of flax: linseed (intermediate flax) and fibre flax. Fibre flax is grown to produce fiber and linseed is grown to get seeds [4-6]. Seeds of both types of flax are used in the food, perfumery, oil and paint and varnish industries as well as in fodder production for animals [7]. The flax stem of both types of flax is used for the production of fabrics, paper, cardboard, fuel briquettes, fertilizers, compositional, non-woven and building materials [8]. The technologies of harvesting two types of flax are different $[9,10]$. This is due to the morphological differences of plants and technology for their further processing. Different technologies of harvesting involve the use of different harvesting machinery for two types of flax [11,12]. Fibre flax is mainly grown to produce a long flax fibre. Therefore, during harvesting, it is important to ensure the parallelism of flax stems in the band, as it is necessary for subsequent technological operations. That's why the specialized machinery (flax puller, flax combine) is used for harvesting of fibre flax [13]. The specialized machinery is equipped with flax pulling mechanisms of different types: belt, screw, roller, vibrating and chain. The most common are belt flax pulling mechanisms. A large number of scientific studies of leading scientists in the field of flax harvesting are devoted to the theoretical determination of the design and parameters of these flax-pulling mechanisms [14]. These flax pulling mechanisms provide high quality flax and parallelism of the stems in the flax band. But these flax pulling mechanisms are bulky, have a complicated design and drive. Cereals combine harvesters are used to harvest linseed. The presence of fiber in stems of linseed flax complicates the operation of the cutting mechanism of grain harvesters and causes frequent break downs. In addition, while cutting the stems a significant part of the fiber is lost on the field with stubble.

Modern processing technologies of linen raw materials provide the use of short fiber with linseed and fibre flax $[15,16]$. This allows us to use the universal technology for harvesting two types of flax. This technology provides preservation of all components of flax crop without cost and damage. During the processing of flax into a short flax fibre according to new technologies, there is no need for the stems in the band to be parallel, even damage to the stems and their rupture is allowed. Thus, for flax harvesting, which is processed into a short flax fibre, it is possible to use flax pulling mechanisms of a simpler design, which should provide only the pulling out of all flax plants from the soil. Therefore, studies toward the development of simple design of flax pulling mechanism and its parameters are relevant. Thus, the scientific 
hypothesis has been put forward, which suggests the possibility of using the conical-disk flax pulling mechanism for the harvesting of linseed and fibre flax, grown in the conditions of the Western Polissya of Ukraine and intended for processing into short fibre.

The goal of the study is to determine the design parameters of the conical-disk flax pulling mechanism, which will allow the linseed and fibre flax pulling out from the soil. To achieve the goal of the study, it is necessary to solve a number of problems. First, it is necessary to determine experimentally the technical and total length of flax stem grown in natural and climatic conditions of the Western Polissia of Ukraine. In addition, it is important to know the force $F_{1}(\mathrm{~N})$ of the resistance to pulling stems out of the soil and breaking load $Q(\mathrm{~N})$ the stems of flax. If the condition $F_{1}<Q$ is not fulfilled, the stems will be broken off while pulling out. Failure to fulfill condition will lead to loss of the stem part of flax plant. During the process of pulling out the stems of fibre flax are not broken, but there is no research of the process of pulling out the stems of linseed, grown in the conditions of the Western Polissya of Ukraine. Scientists have determined only the breaking load $Q$ $=45-145 \mathrm{~N}$ [17] of the stems of linseed. It is also necessary to determine the condition for pulling out the stems from the soil with flax pulling mechanism and design parameters of this mechanism.

Material and methods. The technical length $l_{1}(\mathrm{~m})$ and total length $l_{2}(\mathrm{~m})$ of the stems of linseed was measured according to the scheme, shown in Fig. 1 . The technical length $l_{1}$ was determined as the distance from the root to the beginning of the branching of the lowest inflorescence for multi-stem flax. Average value of length and interval of variation were calculated by the results of experiments.

Determination of force $F_{1}(\mathrm{~N})$ of resistance of pulling out the stems of linseed from the soil was carried out on three varieties of linseed: Blue-orange, Liryna and Southern Night. Number of stems of each variety of linseed pulled out from the soil was 300 plants. Force $F_{1}$ was measured by using a dynamometer with a special clamp, which was fixed on the stem (Fig. 1). Clamp was fixed on the stem at a height $l_{0}=0.05 \mathrm{~m}$ from the root. If the plant of linseed had several stems, then the clamp was fixed to the middle stem. This is due to the fact that during pulling out the force $F_{1}$ can be applied to only one stem of the plant. 


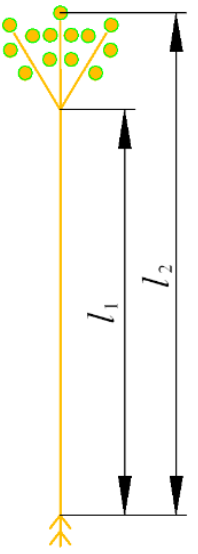

a

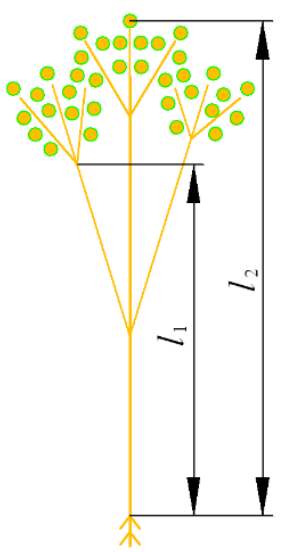

$\mathrm{b}$

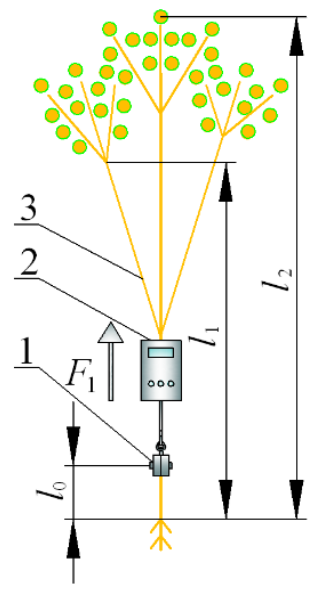

c

Figure 1 - Schemes of measurement the technical length $l_{1}$ and total length $l_{2}$ of single (a) and multi-stem (b) plants of linseed and the force $F_{1}(\mathrm{c}): 1$ - clamp; 2 - dynamometer; 3 - stem of flax

Diameter of the stems was measured at the place of clamping the stem. The influence of the angle of deviation of the stems from the vertical position on the value of the resistance force to pulling the stems from the soil was also studied. During the study, the angle $\beta$ of deviation of the stems from the vertical position was 0.392 and 0.785 rad. In addition, the number of broken stems during pulling out of the ground was recorded. The humidity of linseed stems and soil moisture were determined by standard methods. The humidity of the linseed stems during the study was in the range of $32-36 \%$. The moisture content of sod-podzolic soil was $13.5 \%$.

Theoretical study was carried out taking into account the fundamental principles of theoretical mechanics and mechanics of plant materials. Processing of experimental data was carried out using methods of mathematical statistics using the software MathCAD14.

Results and discussion. Design of conical-disk flax pulling mechanism is proposed for pulling out the stems of linseed and fibre flax (Fig. 2). Conical-disc flax pulling mechanism can be installed on the flax puller of a new design or on cereals combine harvesters with different width instead of cutting mechanism, for example, combines of firms John Deere, New Holland. The same conical-discs are fixed on the shaft 
of the flax pulling mechanism. Two adjacent disks form the pulling section. The surface of the discs is covered with friction material. The flax pulling mechanism is equipped with a cleaning bar with teeth, the ends of which fall into the gap between the conical discs. The flax pulling mechanism has a compact design and a simple drive.

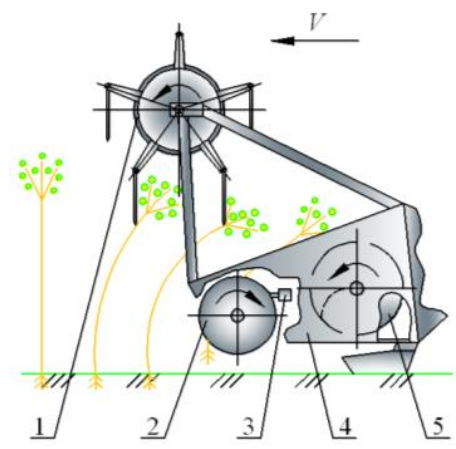

a

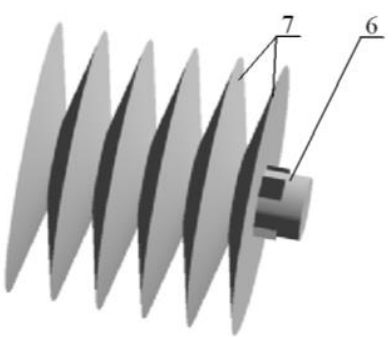

b

Figure 2 - Scheme of grain platform body with conical-disk flax pulling mechanism (a) and its fragment (b): 1 - reel; 2 - flax pulling mechanism; 3 - cleaning bar; 4 - grain platform body; 5 - auger; 6 shaft; 7 - conical disks

During the process of pulling out the stems of flax with conicaldisk flax pulling mechanism can distinguish two stages:

- tightening the stem between the conical discs and its jamming occurs at the first stage;

- pulling out the stem jammed between the conical discs from soil takes place at the second stage.

Examine the process of pulling out the stem of flax with conical-disk flax pulling mechanism installed at a height $h(\mathrm{~m})$ above the surface of the field on the flax puller. The flax puller moves along lines of flax with speed $V(\mathrm{~m} / \mathrm{s})$ (Fig. 3). Stem of flax contacts with surfaces of two conical disks during the process of pulling out the flax. Conical disks are rotating with the same angular velocity $\omega(\mathrm{rad} / \mathrm{s})$. Set the coordinate system $x y$ as shown in Figure 3. The axis $x$ will be directed in the plane $S_{1}$ perpendicular to the stem in the direction opposite to the direction of tightening the stem between discs. The axis $y$ will be directed parallel to the stem upwards. 
Consider the process of tightening the stem between the conical discs from the moment of its contact with two conical disks simultaneously. Two cases are possible at this stage of pulling out. In the first case, the stem is tightened between the conical discs in an upright position (Fig. 3a). In the second case, the stem is deviates between the conical discs from the vertical position to the angle $\beta$ (Fig. 3b), until the next stems start to support it. Since the first case is unlikely, consider the second case. In addition, the first case is described by the same equations as the second one. Suppose that during deviation the stem remains straightforward. Force of normal pressure $N(\mathrm{~N})$, directed in the plane $S_{1}$ perpendicular to the surface of the disk, acts on the stem from each conical disk (Fig. 4). Due to the contact of flax stem with conical discs having the same surfaces, there are two identical frictional forces $F_{f}=f \cdot N$ (N) (where $f$ is a coefficient of friction of flax stem on the surface of the conical disk).

The forces of friction $F_{f}$ try to tighten the stem simultaneously to the discs space and pull it out from the soil. Each of the forces of friction $F_{f}$ will be divided into two components: the component $F_{f 1}(\mathrm{~N})$ directed along the surface of a conical disk in the plane $S_{1}$ causes tightening of the stem between discs; the component $F_{f 2}(\mathrm{~N})$ directed parallel to the axis $y$ along the stem upwards, tries to pull the stem out from the soil. In addition, the force $F_{1}(\mathrm{~N})$ of the resistance of pulling out the stem from soil, the force $F_{2}(\mathrm{~N})$ of the resistance of the stem deviation from the vertical position, the force $F_{3}(\mathrm{~N})$ of the resistance of the flax stem deviation from the vertical position from the side of the unselected stems act on the stem.

The tightening of the flax stem will take place if it moves along the negative direction of axis $x$. This is possible if the condition is fulfilled (Fig. 4b):

$$
2 F_{f 1} \cdot \cos \alpha+\left(F_{2}+F_{3}\right) \cdot \cos \beta>2 N \cdot \sin \alpha
$$

where $\alpha$ - the angle of the conical disk, rad.

Force $F_{2}$ resistance of the stem to deviation from the vertical position:

$$
F_{2}=\frac{3 \Delta E J}{h^{3}},
$$

where $\Delta-$ the deviation of stem from vertical position, $\mathrm{m} ; E J-$ the stiffness of the flax stem, $\mathrm{N} \cdot \mathrm{m}^{2}$. 


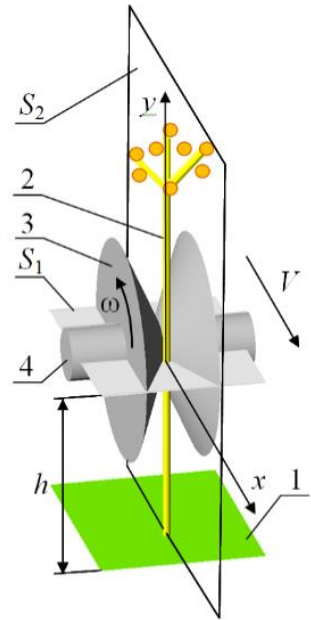

a

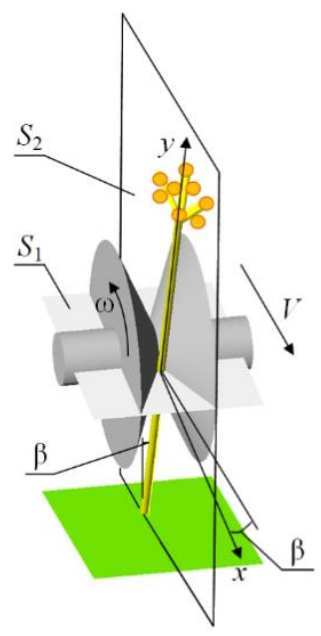

b

Figure 3 - Schemes of interaction stem of flax with conical-disk flax pulling mechanism at the angles of deviation of the stem $\beta=0 \mathrm{rad}$ (a) and $\beta>0 \operatorname{rad}(b): 1$ - surface of the field; 2 - stem of flax; 3 - conicaldisk flax pulling mechanism; 4 - shaft

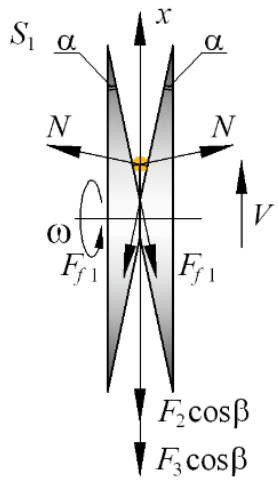

a

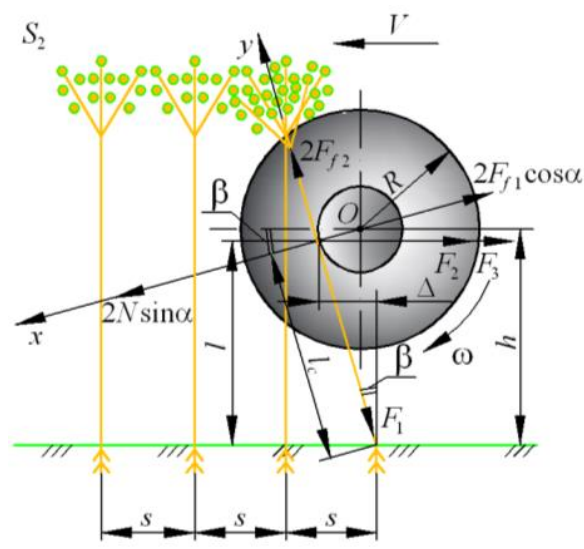

b

Figure 4 -Schemes of action forces on the stem in planes $S_{1}$ (a) and $S_{2}$ (b) during its tightening between the conical disks

Let's assume that the largest deviation of the stem from the vertical position is equal to the distance $s(\mathrm{~m})$ between the plants of the 
flax in the row. In this case $(\Delta=s)$, the angle of maximum deviation of the stem from the vertical position:

$$
\operatorname{tg} \beta=\frac{\Delta}{l}=\frac{\Delta}{\sqrt{l_{c}^{2}-\Delta^{2}}}=\frac{s}{\sqrt{h^{2}-s^{2}}}, \beta=\operatorname{arctg}\left[\frac{s}{\sqrt{h^{2}-s^{2}}}\right],
$$

where $l$ - the height at which the stem is tightened between the conical discs, $\mathrm{m} ; l_{c}$ - the length of the straight-line stem from the root to the tightening point between the disks, $\mathrm{m}$.

For further theoretical study, the force $F_{2}$ is determined by the Eq.(2), having accepted $\Delta=s$. The forces $F_{1}$ and $F_{3}$ are determined experimentally, because they depend on a number of factors: varietal features of flax, condition of plant stand of flax, crop density and other factors.

Consider the second stage of pulling out the stem. Determine the condition of pulling out the stem from the soil with the conical disks of the pulling mechanism (Fig. 5). Let's assume that the stem of flax is pressed to the surfaces of conical disks of one pulling section by forces $F_{2}$ and $F_{3}$. Moreover, the stem contacts the conical disks at two points. Condition of pressing the stem to the surfaces of conical disks:

$$
\left(F_{2}+F_{3}\right) \cdot \cos \beta \geq 2 N \cdot \sin \alpha \text {. }
$$

At the moment of tightening of the stem between the discs, the Eq.(4) takes the form:

$$
\left(F_{2}+F_{3}\right) \cdot \cos \beta=2 N \cdot \sin \alpha .
$$

The force $F_{f}$ acts on the stem from the side of each disc and is directed parallel to the axis $y$ and tries to pull out the stem from the soil. Condition for pulling out the stem from the soil:

$$
2 F_{f}>F_{1}+\left(F_{2}+F_{3}\right) \cdot \sin \beta \text {. }
$$

At the initial moment of pulling out the stem force $F_{f}$ reaches the maximum value:

$$
F_{f}=f N=\frac{f\left(F_{2}+F_{3}\right) \cos \beta}{2 \sin \alpha} .
$$




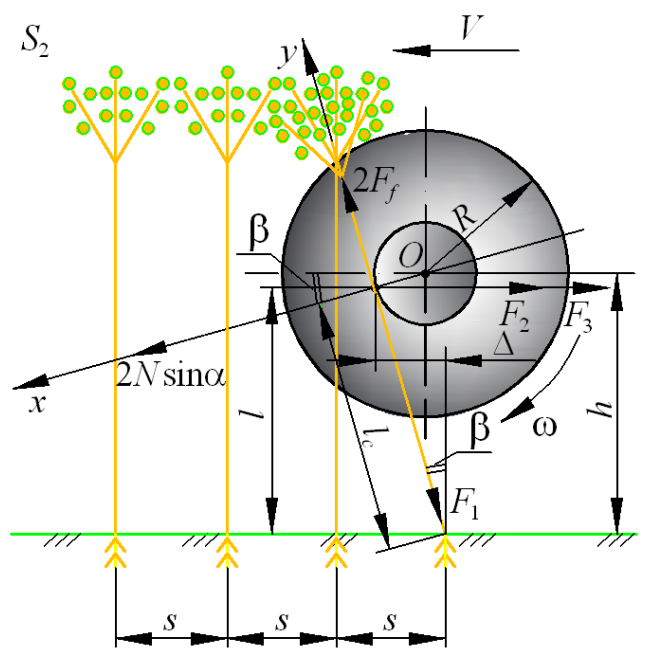

Figure 5 - Scheme of action forces on the stem in plane $S_{2}$ during its pulling out from the soil

So, condition for pulling out the flax stem from the soil:

$$
\frac{f\left(F_{2}+F_{3}\right) \cos \beta}{\sin \alpha}>F_{1}+\left(F_{2}+F_{3}\right) \sin \beta .
$$

From the condition (8) we will determine what should be the angle $\alpha$ for pulling out the flax stem from the soil with the conical discs:

$$
\alpha<\arcsin \left[\frac{f\left(F_{2}+F_{3}\right) \cos \beta}{F_{1}+\left(F_{2}+F_{3}\right) \sin \beta}\right] .
$$

Diagrams $\alpha\left(\beta, F_{1}\right)$ (Fig. 6) showing the most permissible values of the angle $\alpha$ are got with known values of angle $\beta$ and force $F_{1}$. Analyzing the diagrams, we can conclude that with an increase in the angle $\beta$ and force $F_{1}$ the most permissible value of the angle $\alpha$ decreases. At the height of installation of flax pulling mechanism $h=0.35 \mathrm{~m}$ and the distance between the plants of flax $s=0.04 \mathrm{~m}$ the maximum value of the angle of deviation of the stem from the vertical position is equal $\beta=0.115$ rad. In the sense of forces $F_{1}=100 \mathrm{~N}, F_{2}=0.028 \mathrm{~N}, F_{3}=55 \mathrm{~N}$ and $f=0.45$ for pulling out the stem from the soil angle $\alpha$ value must not exceed $\alpha<$ $0.233 \mathrm{rad}$. 


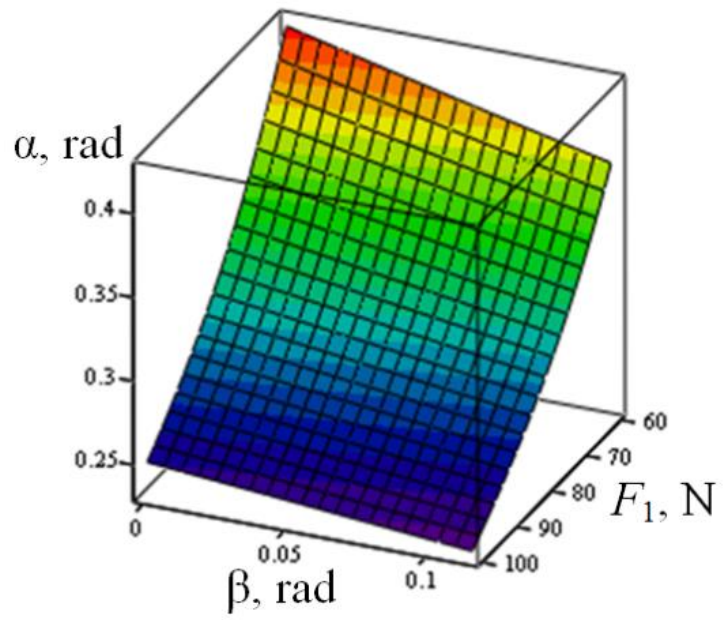

Figure 6 - Diagrams showing the impact of the angle $\beta$ and force $F_{1}$ on the angle $\alpha\left(F_{2}=0.028 \mathrm{~N}, F_{3}=55 \mathrm{~N}, f=0.45\right)$

According to the results of the study (Fig. 7a), the technical length $l_{1}$ of the stems of linseed is: for the Blue-orange variety $l_{1}=0.37 \pm 0.03 \mathrm{~m}$; for the Liryna variety $-l_{1}=0.40 \pm 0.02 \mathrm{~m}$; for the Southern Night variety $-l_{1}=0.47 \pm 0.04 \mathrm{~m}$. The technical length $l_{1}$ of the stems must be greater than the radius $R=0.24 \mathrm{~m}$ of the conical disks of flax pulling mechanism. If $l_{1}<R$, then tightening of the stems with discs will occur at the level of the inflorescences. This will result in loss and damage to the seed portion of the crop. The total length $l_{2}$ of the stems of linseed is: for the Blue-orange variety $-l_{2}=0.64 \pm 0.04 \mathrm{~m}$; for the Liryna variety $-l_{2}=0.66 \pm 0.03 \mathrm{~m}$; for the Southern Night variety $-l_{2}=0.73 \pm 0.04$ $\mathrm{m}$. So, the technical length and total length of the stems of linseed, grown in the conditions of the Western Polissya of Ukraine, allows their pulling out from the soil with conical-disk flax pulling mechanism.

The analysis of the research results (Fig. 7b) shows that the force of resistance of pulling out the stems of linseed from the soil for different varieties is changing from $F_{1 \min }=13 \mathrm{~N}$ to $F_{1 \max }=92 \mathrm{~N}$. Comparison of force $F_{1}$ with force $Q$ [17] for linseed varieties Blueorange, Liryna and Southern Night shows that only linseed varieties Liryna and Southern night can be harvested by way of pulling out from the soil because: for the variety Liryna $F_{1 \max }=61 \mathrm{~N}<Q=125 \mathrm{~N}$; for the variety Southern Night $F_{1 \max }=58 \mathrm{~N}<Q=145 \mathrm{~N}$. It is necessary to use the cutting of stems for the Blue-orange variety because for this variety $F_{1 \max }=92 \mathrm{~N}>Q=80 \mathrm{~N}$. Thus, not all varieties of linseed can be harvested 
by way of pulling out because it will lead to damage and breakage of stems. Processing of experimental data showed that the average force $F_{1}$ and the standard deviation $S_{c}$ are: for the variety of Blue-orange $F_{1}=53.2 \mathrm{~N}, S_{c}= \pm 22.7 \mathrm{~N}$; for the variety of Liryna $-F_{1}=41.7 \mathrm{~N}, S_{c}= \pm 11.3$ $\mathrm{N}$; for the variety Southern Night $-F_{1}=37.6 \mathrm{~N}, S_{c}= \pm 11.7 \mathrm{~N}$. Number of broken linseed stems during the study of their pulling out from the soil was within $3.2-7.8 \%$. The most percentage of broken stems is $7.8 \%$ among linseed stems of Blue-orange variety.

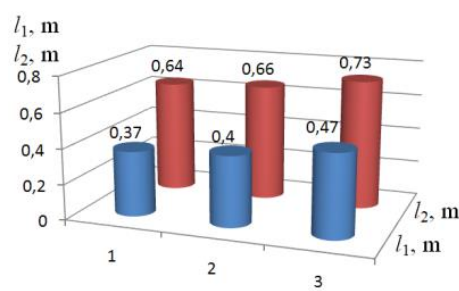

a

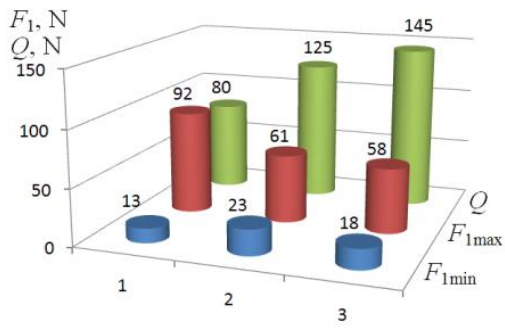

b

Figure 7 - The measurement results $(1$ - variety of flax Blueorange; 2 - variety of flax Liryna; 3 - variety of flax Southern Night): a - technical length $l_{1}$ and total length $l_{2}$ of the linseed stems; b - force $F_{1}$ and force $Q$

Diameters of the linseed stems in place of the clamp were as follows: for variety Blue-orange $-3.3 \pm 0.3 \mathrm{~mm}$; for variety Liryna $2.9 \pm 0.4 \mathrm{~mm}$; for variety Southern Night $-2.7 \pm 0.3 \mathrm{~mm}$. As a result of studies of the effect of the diameter of the stems and the angle $\beta$ to the value of the resistance force to the pulling out the stems from the soil it was found that the relationship between these values is missing, because the value of correlation coefficient is $r_{c}=0$. In our opinion, the strength of resistance to pulling out the stems from the soil is influenced with other factors, such as the branching of the root system and its condition, as well as the type and micro relief of the soil, density and soil moisture.

Conclusions. The conducted theoretical and experimental studies indicate the possibility of using the conical-disk flax pulling mechanism with determined design parameters for the harvesting of linseed and fibre flax, which are intended for processing into short fibre. The theory of the process of flax pulling out with the flax pulling mechanism has been expanded in the article. As a result of the study, the condition of pulling out the flax stems from the soil with conical-disk flax pulling mechanism was obtained. This allows us to determine the 
rational design parameters of conical disks: the radius of the smaller base of the conical disk is $r=0.03 \mathrm{~m}$; the radius of the larger base of the conical disk is $R=0.243 \mathrm{~m}$; the angle is $\alpha=0.174 \mathrm{rad}$; the height of the installation of the disks above the ground is $h=0.3 \mathrm{~m}$; the width of the capture of one section is $0.075 \mathrm{~m}$. At the speed of movement of the flax harvesting machinery $V=0.833 \mathrm{~m} / \mathrm{s}$ the angular velocity of the disks of the conical-disc flax pulling mechanism should be $\omega=45 \mathrm{rad} / \mathrm{s}$.

It was determined that the technical length of the stems of linseed varieties Liryna and Southern Night is within the limits of $l_{1}=0.40-0.47 \mathrm{~m}$ and force of resistance of pulling out the stems of flax is within the limits of $F_{1}=18-61 \mathrm{~N}$. These values indicate that for harvesting varieties Liryna and South Night of linseed and all varieties of fibre flax can be used the conical-disk flax pulling mechanism, which was proposed.

\section{References}

1. Feng-zhi, G. (2007). The problem and suggestions of flax industry development. Plant Fiber Sciences in China, 2. Available at http://en.cnki.com.cn/Article_en/CJFDTOTAL-ZGMZ2007S2007.htm

2. Uschapovsky, I. (2009). The Russian flax sector: bottlenecks and solutions. Journal of Natural Fibers, 6(1), 108-113.

3. Yang, R.B., Li, X.J., Tan, S.L. (2009). Development survey and prospect of flax industry. Modern Agricultural Sciences, 4. Available at http://en.cnki.com.cn/Article_en/CJFDTOTAL-NCSY200904121.htm

4. Foulk, J.A., Akin, D.E., Dodd, R.B. (2003). Fiber flax farming practices in the Southeastern United States. Crop Management, 2(1). Available at https://doi.org/10.1094/CM-2003-0124-01-MG

5. Hall, L.M., Booker, H., Siloto, R.M.P., Jhala, A.J., Weselake, R.J. (2016). Flax (Linum usitatissimum L.). Industrial Oil Crops, 157-194. Available at https://doi.org/10.1016/B978-1-893997-98-1.00006-3

6. Heller, K., Sheng, Q.C., Guan, F., Alexopoulou, E., Hua, L.S., Wu, G.W., Jankauskiene, Z., Fu, W.Y. (2015). A comparative study between Europe and China in crop management of two types of flax: linseed and fibre flax. Industrial Crops and Products, 68, 24-31.

7. Verghese, M., Boateng, J., Walker, L.T. (2011). Flax seed (Linum usitatissimum) fatty acids. Nuts and Seeds in Health and Disease Prevention, 487-498. Available at https://doi.org/10.1016/B978-0-12375688-6.10058-1

8. Liu, Z., Erhan, S.Z., Akin, D.E., Barton, F.E. (2006). "Green" composites from renewable resources: preparation of epoxidized soybean oil and flax fiber composites. Journal of Agricultural and Food Chemistry, 54(6), 2134-2137. 
9. Mańkowski, J., Maksymiuk, W., Spychalski, G., Kołodziej, J., Kubacki, A., Kupka, D., Pudełko, K. (2017). Research on new technology of fiber flax harvesting. Journal of Natural Fibers, 15(1), 5361.

10. Souček, J., Šturc, T., Mareček, J. (2017). Analysis of linseed production with use of flax puller and combine harvester for its harvest. Acta Univ. Agric. Silvic. Mendelianae Brun, 65, 511-517.

11. Tribunalov, M.N., Garost, M.M. (2012). Comparative evaluation of technologies of flax harvesting. Mechanization and Electrification of Agriculture: interdepartmental subject collection. Available at http://agris.fao.org/agris-search/search.do?recordID=BY2013

12. Pari, L., Baraniecki, P., Kaniewski, R., Scarfone, A. (2015). Harvesting strategies of bast fiber crops in Europe and in China. Industrial Crops and Products, 68, 90-96.

13. Lihui, G., Haifeng, C., Liming, Z., Yong, G., Bangxing, G., Zhengping, L. (2009). Development of 4FZ-140 type self-propelled flax harvester [J]. Journal of Agricultural Mechanization Research, 6. Available at http://en.cnki.com.cn/Article_en/CJFDTOTALNJYJ200906021.htm

14. Хайлис, Г.А. Быков, Н.Н., Бухарин, В.Н. (1985). Льноуборочные машины. М.: Машиностроение, 232 с.

15. Nilsson, D. (2003). Harvesting and handling of flax for the production of short fibres under Swedish conditions. A literature review. Available at https://pub.epsilon.slu.se/3966/1/nilsson_d_090930.pdf

16. Nilsson, D. (2006). Dynamic simulation of the harvest operations of flax straw for short fibre production - Part 1. Journal of Natural Fibers, 3(1), 23-34.

17. Сай, В.А. (2012). Технологія вирощування, збирання та первинної переробки льону олійного: монографія. Луцьк: ЛНТУ, $168 \mathrm{c}$. 